Roger Williams University

DOCS@RWU

\title{
Functional Morphology and Fluid Interactions During Early Development of the Scyphomedusa Aurelia Aurita
}

\author{
K. E. Feitl \\ Providence College
}

A. F. Millett

Roger Williams University

Sean Colin

RogerWilliams University, scolin@rwu.edu

John O. Dabiri

California Institute of Technology

John H. Costello

Providence College

Follow this and additional works at: https://docs.rwu.edu/fcas_fp

Part of the Biology Commons

\section{Recommended Citation}

Feitl, K. E., A. F. Millett, Sean P. Colin, J.O. Dabiri, J. H. Costello. 2009. "Functional Morphology and Fluid Interactions During Early Development of the Scyphomedusa Aurelia Aurita." The Biological Bulletin 217 (3): 283-291.

This Article is brought to you for free and open access by the Arts and Sciences at DOCS@RWU. It has been accepted for inclusion in Arts \& Sciences Faculty Publications by an authorized administrator of DOCS@RWU. For more information, please contact mwu@rwu.edu. 


\title{
Functional Morphology and Fluid Interactions During Early Development of the Scyphomedusa Aurelia aurita
}

\author{
K. E. FEITL ${ }^{1, *}$, A. F MILLETT ${ }^{2, \dagger}$, S. P. COLIN $^{2}$, J. O. DABIRI ${ }^{3}$, AND J. H. COSTELLO ${ }^{1} \ddagger$ \\ ${ }^{1}$ Biology Department, Providence College, Providence, Rhode Island 02918-0001; ${ }^{2}$ Environmental \\ Sciences, Roger Williams University, One Old Ferry Rd., Bristol, Rhode Island 02809; and ${ }^{3}$ Graduate \\ Aeronautical Laboratories and Bioengineering, Mail Code 138-78, California Institute of Technology, \\ Pasadena, California 91125
}

\begin{abstract}
Scyphomedusae undergo a predictable ontogenetic transition from a conserved, universal larval form to a diverse array of adult morphologies. This transition entails a change in bell morphology from a highly discontinuous ephyral form, with deep clefts separating eight discrete lappets, to a continuous solid umbrella-like adult form. We used a combination of kinematic, modeling, and flow visualization techniques to examine the function of the medusan bell throughout the developmental changes of the scyphomedusa Aurelia aurita. We found that flow around swimming ephyrae and their lappets was relatively viscous $(1<\operatorname{Re}<10)$ and, as a result, ephyral lappets were surrounded by thick, overlapping boundary layers that occluded flow through the gaps between lappets. As medusae grew, their fluid environment became increasingly influenced by inertial forces $(10<\operatorname{Re}<10,000)$ and, simultaneously, clefts between the lappets were replaced by organic tissue. Hence, although the bell undergoes a structural transition from discontinuous (lappets with gaps) to continuous (solid bell) surfaces during development, all developmental stages maintain functionally continuous paddling surfaces. This developmental pattern enables ephyrae to efficiently allocate tissue to bell diameter increase via lappet growth, while minimizing tissue allocation to inter-lappet spaces
\end{abstract}

Received 7 May 2009; accepted 1 September 2009.

* Current address: Department of Ecology \& Evolution, 321 Steinhaus Hall, University of California, Irvine, CA 92697.

$\dagger$ Current address: 101 Bienville Blvd., Dauphin Island, AL 36528.

\$ To whom correspondence should be addressed. E-mail: costello@providence.edu that maintain paddle function due to boundary layer overlap.

\section{Introduction}

Prey capture is related to fluid flows generated during swimming by both adult (Costello and Colin, 1994, 1995; Ford et al., 1997; D'Ambra et al., 2001; Dabiri et al., 2005) and ephyral (Sullivan et al., 1997; Higgins et al., 2008) scyphomedusae. Among semaeostome and rhizostome taxa, medusae of all life stages spend the majority of time swimming (Costello et al., 1998) and generate flow patterns that transport entrained prey to nematocyst-laden capture surfaces. The morphology and placement of the capture surfaces vary among adult scyphomedusae, but most species possess a nearly continuous bell that pulses to generate circulation in the surrounding fluid (Costello and Colin, 1995; Dabiri et al., 2007; Costello et al., 2008).

Ephyrae (juvenile scyphomedusae, Fig. 1) possess notably different morphologies than their adult counterparts. This is true for all scyphomedusan species except some coronate medusae, such as the genus Nausithöe, whose adults are relatively small (bell diameters generally less than $2 \mathrm{~cm}$ ) and ephyra-like in form. Instead of a continuous, circular disk, ephyral bells characteristically possess deep clefts between lappets (Fig. 2). Unimpeded fluid flow through these inter-lappet clefts during the bell contraction cycle could result in a sieving function for the ephyral bell that would contrast sharply with the function of solid bells characteristic of adult medusae during swimming. However, if the boundary layers around the adjacent lappets are large relative to the gap between them, flow between the lappets 


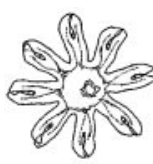

$0.36 \mathrm{~cm}$
$0.44 \mathrm{~cm}$

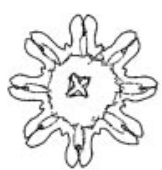

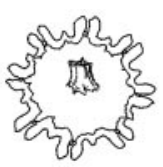

$0.74 \mathrm{~cm}$

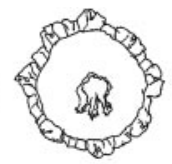

$1.09 \mathrm{~cm}$

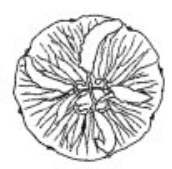

$2.88 \mathrm{~cm}$
Figure 1. Developmental stages and representative bell diameters during the life history of the medusa Aurelia aurita. Bell diameters are listed below each size stage.

would be greatly reduced (Koehl, 2006). As a result, the discontinuous morphological structure of the ephyral bell would function as a hydrodynamically continuous surface, and hence a single "paddle," during ephyral swimming. Surrounding water would then pass around, rather than through, the inter-lappet clefts and allow the ephyral bell to function analogously to the adult bell despite the strikingly different morphologies of the two life stages. Such scaledependent phenomena can be important during development because they can alter the dominant propulsive forces experienced by developing planktonic organisms (e.g., Williams, 1994a, b; Bartol et al., 2008).

Previous studies of ephyral prey capture by two semaeostome scyphomedusan ephyrae, Aurelia aurita (Sullivan et al., 1997) and Cyanea capillata (Higgins et al., 2008), support the viability of the paddle hypothesis because those studies indicated that prey-containing water appeared to flow around, not through, the ephyral bell. In addition, previous research on small crustaceans and insects demonstrated that flows through gaps between adjoining cylindrical elements in setal arrays can be diminished by the relatively thick boundary layers at low and intermediate Re flows (Cheer and Koehl, 1987a, b; Koehl, 1998) and that variations in flexible element spacing during motion can further decrease flow between adjacent appendage elements (Fernier and Gaylord, 2008).

Our goal in this study was to detail lappet boundary layer dynamics during ephyral swimming in order to evaluate the suitability of viewing the ephyral bell as a hydrodynamically continuous structure during development. The issue of size-dependence is important because small ephyrae (several millimeters in bell diameter) grow to substantially larger adult medusae (many centimeters in bell diameter; e.g., Kawahara et al., 2006), changing the Reynolds number of the flows around the medusae substantially. Additionally, lappets are not rigidly positioned cylinders but flexible elements that change orientation with respect to one another during bell pulsation. The kinematics of these positional changes could influence fluid flows. The scyphomedusa Aurelia aurita presents a useful test organism for examination of these questions because of its cosmopolitan distribution (Kramp, 1961), ecological relevance (e.g., Behrends and Schneider, 1995), and the relative ease with which it can be maintained in the laboratory.

\section{Materials and Methods}

\section{Experimental animals}

Individuals of Aurelia aurita (Linnaeus 1758) ranging in size from newly budded ephyrae $(0.25 \mathrm{~cm})$ to fully mature medusae $(10.0 \mathrm{~cm})$ were obtained from cultures of strobilating polyps maintained by the New England Aquarium in Boston, Massachusetts. Animals were maintained in 64$\mu \mathrm{m}$-filtered seawater at temperatures ranging from 12-16 ${ }^{\circ} \mathrm{C}$ and were fed newly hatched Artemia sp. three or four times weekly.

\section{Video recording}

To visualize the movement of fluid around the bells of freely swimming medusae, individuals were placed in 64$\mu \mathrm{m}$-filtered seawater in glass vessels with dimensions ranging from $4.0 \times 8.0 \times 2.0 \mathrm{~cm}$ to $25.2 \times 30.4 \times 18.4 \mathrm{~cm}$ (width $\times$ height $\times$ depth). While smaller vessels were used for smaller medusae, vessel depths were more than 5 times the animal diameter in order to avoid wall effects (Vogel, 1994; Loudon et al., 1994).

To quantify flows around the bells of swimming medusae, Artemia salina cysts were added to the filtered seawater in the vessel and stirred until suspended throughout the water column. Each animal was filmed freely swimming for about 15-20 min, using a standard rate/standard definition Pulnix CCD camera $(720 \times 480$ pixel resolution, 30 frames per second) and a backlit optical system (Costello and Colin, 1994). Kinematics of ephyral lappets and the movement of fluid around the lappets were filmed at higher frame rates (250 frames per second) using a Fastcam Super 10K video camera (Photron Inc.; $512 \times 480$ pixel resolution) These higher speed recordings were of shorter duration, and the ephyrae remained in the recording vessels for no longer

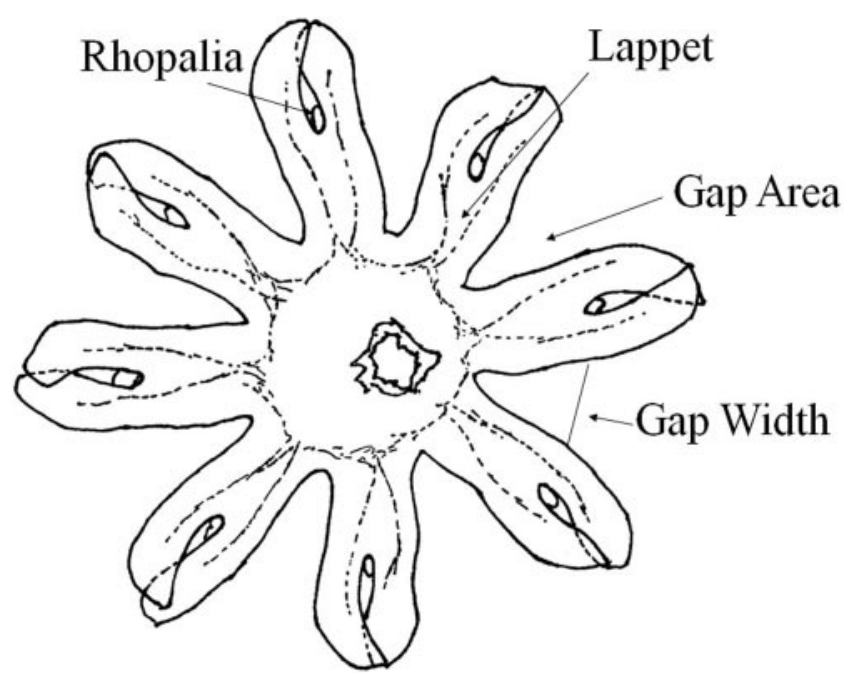

Figure 2. Ephyral stage morphology of Aurelia aurita. 
than 5 min. All video was recorded onto mini-DV tape and analyzed using Adobe Premiere Pro 2.0 and ImageJ 1.3x (developed by the NIH) software.

\section{Analysis of fluid environment}

The fluid environment surrounding swimming animals was examined using both fluorescein dye visualizations (Dabiri et al., 2005) and particle tracks. To obtain particle tracks, we followed the position of Artemia salina cysts in the fluid adjacent to the bell margin for 3 to 5 consecutive frames during the power stroke of bell pulsation (Costello and Colin, 1994; Dabiri et al., 2005). To exclude motion in the unmeasured third dimension, we only analyzed sequences in which the animals were oriented perpendicularly to the camera view and the particles remained in focus throughout the sequence (Costello and Colin, 1994). We calculated particle velocities $\left(u_{p}\right)$ on the basis of displacement of the particles over time. From these, the maximum Reynolds number of the fluid flows around the bell was calculated using the formula

$$
\operatorname{Re}_{B}=\frac{D u_{p}}{v}
$$

where $D$ was bell diameter, and $\nu$ was the kinematic viscosity of seawater (Vogel, 1994; Colin and Costello, 2002). Bell diameter, including the extended lappets, was used as the characteristic length scale since we were estimating the Re of the flow around the whole animal.

\section{Morphometric analysis}

Bell morphology data were collected from images in which the medusa was maximally relaxed and the oral surface was oriented perpendicular to the camera. Potential bell area, which represents the theoretical maximum bell area of an ephyra with inter-lappet gaps completely filled in with tissue, was calculated assuming a circle of diameter $D$. For each ephyra, the areas between at least three lappets, termed the gap area, were measured by outlining the fluidlappet boundary of two adjacent lappets (Fig. 2), using the area measure function in the computer program ImageJ. To calculate the total gap area, we averaged the measured areas and multiplied the average by 8 (the total number of gaps per individual). The total gap area was used to estimate bell continuity $\left(\mathrm{BC}_{\mathrm{E}}\right)$, which we defined as the percent of the bell area composed of tissue:

$$
\mathrm{BC}_{\mathrm{E}}=\left(\frac{\text { potential bell area }- \text { total gap area }}{\text { potential bell area }}\right) 100 .
$$

\section{Kinematic profile}

To examine the kinematic profile of a swimming ephyra and its lappets, we used video ( $250 \mathrm{fps}$ ) of a $0.32-\mathrm{cm}$ ephyra swimming in $64-\mu \mathrm{m}$-filtered seawater. A sequence in which the animal swam upward perpendicular to the viewing screen for several pulsation cycles was chosen for analysis. Frames were extracted from the video sequence at 0.02 -s intervals (50 fps). Bell height and diameter were measured for each of these intervals. Bell fineness (Daniel, 1983; Costello and Colin, 1994; Dabiri et al., 2007) indicated progress through the bell contraction cycle and was calculated for each interval using the formula:

$$
F=\frac{h}{D}
$$

where $h$ is bell height. The change in position $(x, y)$ of the lappet (using the rhopalia as the reference point; Fig. 2) and the whole animal (using the bell apex as the reference point) were tracked over time and used to calculate lappet velocity throughout the pulsation cycle. Velocity $\left(\mu_{l}\right)$ was calculated as:

$$
u_{l}=\frac{\sqrt{\left(x_{n+1}-x_{n}\right)^{2}+\left(y_{n+1}-y_{n}\right)^{2}}}{\Delta t}
$$

where $x$ and $y$ correspond to the $x$ - and $y$ - coordinates of the rhopalia, $t$ is the time interval between collection of position data, and correction has been made for whole animal motion (the distance the whole animal had moved since the original frame). A local Reynolds number for the lappet $\left(\operatorname{Re}_{L}\right)$ was calculated using Equation 1 but was based upon the width $(d)$ and velocity $\left(\mu_{l}\right)$ of the lappet. $\operatorname{Re}_{L}$ was then used to estimate the boundary layer thickness $\left(\delta_{E}\right)$ around the lappet (Ellington, 1975; Yen et al., 1998),

$$
\delta_{E}=\frac{1}{\sqrt{\mathrm{Re}_{L}}}
$$

where $l$ represents lappet length. Gap distance throughout bell pulsation was measured as the distance between the rhopalia of two adjacent lappets, corrected for the lappet thickness between the rhopalia (Fig. 2). Overlap of boundary layers around adjoining lappets was calculated from the boundary layer dimensions surrounding adjoining lappets.

\section{Developmental model}

The influence of size on the hydrodynamic performance of ephyral bell morphologies was explored with a model created to evaluate the role of the boundary layer around the lappets during scyphomedusan ontogeny. The defining model parameters (Fig. 3) were the central bell disk diameter $D_{0}$, the lappet length $l$ and width $d$, the bell diameter $D$, and the number of lappets $N$. The bell was assumed to be flat during relaxation. Bell continuity for the model $\left(\mathrm{BC}_{\mathrm{M}}\right)$ was defined as the fraction of bell area composed of tissue and expressed as a percentage: 


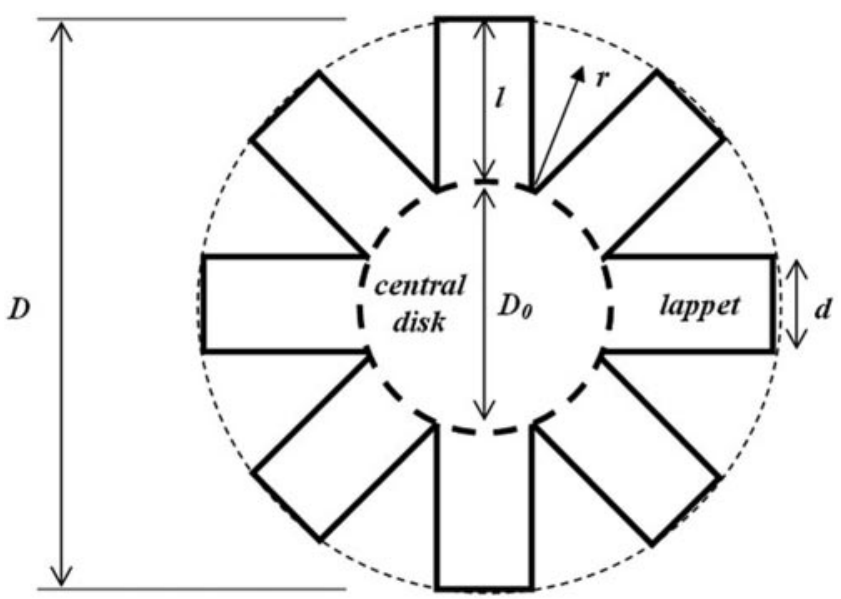

Figure 3. Schematic diagram of bell structures used in model of lappet boundary layer overlap model, including the central bell disk diameter $\left(D_{O}\right)$, the lappet length $(l)$ and width $(d)$, and the bell diameter $(D)$.

$$
\mathrm{BC}_{\mathrm{M}}=\frac{A_{\text {central disk }}+A_{\text {lappets }}}{A_{\text {total }}}
$$

where $A_{\text {central disk }}$ was the area of the central disk, $A_{\text {lappets }}$ was the total area of the lappets, and $A_{\text {total }}$ was the total bell area such that,

$$
A_{\text {central disk }}=\frac{\pi D_{0}^{2}}{4}, A_{\text {lappets }}=N d l, A_{\text {total }}=\frac{\pi D^{2}}{4}
$$

The lappet width $d$ was approximated in terms of the central disk diameter $D_{0}$ as

$$
d \approx \frac{\pi D_{0}}{N}
$$

since the lappets are joined at the central disk. Also, the lappet length $l$ was written in terms of the central disk and total bell diameters $D_{0}$ and $D$ (Fig. 3):

$$
l \approx \frac{D-D_{0}}{2}
$$

Substituting equations (7), (8), and (9) into (6) gives

$$
B C_{M} \approx \frac{2 D_{0}}{D}-\left(\frac{D_{0}}{D}\right)^{2}
$$

We assumed that in order for the medusa bell to function as a continuous hydrodynamic surface, the gap area between the lappets must be less than or equal to the area of the boundary layers formed between the lappets, i.e.,

$$
A_{\text {gap }} \leq A_{B L}
$$

The total gap area was given by

$$
A_{\text {gap }}=A_{\text {total }}-A_{\text {central disk }}-A_{\text {lappets }} .
$$

Substituting equations (7), (8), and (9) into equation (12),

$$
A_{\text {gap }}=\frac{\pi}{4}\left(D-D_{0}\right)^{2}
$$

The area of the boundary layers was determined by integrating the boundary layer thickness - which was a function of radial distance from the central disk (i.e., from $D$ ) - along the length of the lappet:

$$
A_{B L}=2 N \int_{0}^{1} \delta(r) d r
$$

As with empirical estimates (Eqn. 5), the boundary layer thickness in the developmental model $\left(\delta_{M}\right)$ was a function of the Reynolds number and a characteristic length scale:

$$
\delta_{M}(r)=\frac{C d}{\sqrt{\operatorname{Re}(r)}} .
$$

In equation (15), $C$ was a constant of proportionality (0.8), the lappet width $d$ was used as the characteristic length scale, and the Reynolds number was permitted to vary with radial position $r$ (White, 1991). Here, we defined the Reynolds number using the local velocity of the lappet (i.e.. at a distance $r$ from the central disk) as the characteristic velocity, and we used the lappet width $d$ as the characteristic length scale since these are the variables affecting the local fluid dynamics at each section of the lappet. Assuming that the lappet paddled with an angular motion at angular velocity $\omega$, the characteristic velocity was $\omega r$, where $r$ is the radial distance from the central disk (Fig. 3). From these considerations,

$$
\delta_{M}(r)=C \sqrt{\frac{d v}{\omega r}}
$$

where $\nu$ is the kinematic viscosity of water. Substituting into equation (14) and integrating,

$$
A_{B L}=C \sqrt{\frac{8 \pi N \nu D_{0}\left(D-D_{0}\right)}{\omega}} .
$$

Given equations (13) and (17), the condition (11) became

$$
128 C^{2} N \nu D_{0}-\pi \omega\left(D-D_{0}\right)^{3} \geq 0
$$

Equation (18) was solved to express $D_{0}$ in terms of $D$. Hence, $D_{0}$ was eliminated from equation (10), and provided a relationship between $B C_{M}$ and $D$.

\section{Results}

Ephyral swimming involved muscular contractions of the bell that result in highly unsteady motions. During bell 


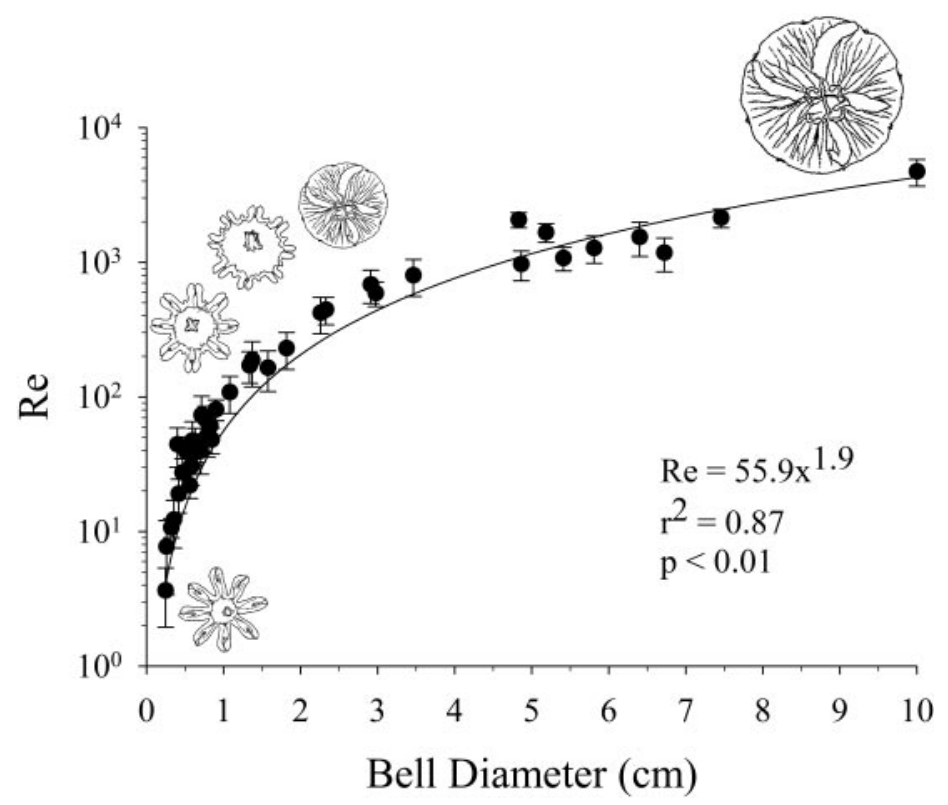

Figure 4. Relationship between bell diameter and Reynolds number $(\mathrm{Re})$ for Aurelia aurita. Re is based on the maximum flow velocity around the contracted bell of individual medusa $(n=39)$. Error bars indicate \pm one standard deviation of the mean; probability value is the result of a one-way ANOVA of original and fitted Re data.

contraction, the lappets swept from an aborally directed configuration through an arc to an opposite orientation on the oral side of the bell. This type of bell motion is different from that of larger medusae whose bell margin is typically oriented toward the oral side of the bell (Costello and Colin, 1994). Subsequent bell relaxation was slower than contraction, and the resulting whole-body swimming velocities were much faster during bell contraction than relaxation (e.g., Higgins et al., 2008). The entire swimming process took place in fluid environments characterized by lower intermediate $\operatorname{Re}_{B}$ values where $1<\operatorname{Re}<100$ at maximum flow velocities surrounding Aurelia aurita ephyrae (Fig. 4). Hence, ephyral swimming occurred in a fluid regime in which both viscous and inertial forces could be highly influential. Size scale strongly affected these interactions, and large specimens of $A$. aurita swam in substantially higher Re flows characterized by maximum $\operatorname{Re}>1000$.

\section{Ephyral lappet kinematics}

Bell lappet kinematics followed overall bell fineness patterns during swimming. Lappet velocities peaked after midcontraction, prior to maximum bell fineness, and were lowest during bell relaxation (Fig. 5). Consequently, the $\mathrm{Re}_{L}$ values around the lappets-ranging from $\operatorname{Re}=0.5-10$ throughout the pulse-were greatest during bell contraction and, because boundary layer thickness is inversely related to Re (Eq. 5), the viscous boundary layers surrounding the lappets became thinner during bell contraction and thicker during bell relaxation. This dynamic change in the boundary layer thickness around lappets was important for whole-bell function because the lappet boundary layers extended into the inter-lappet clefts and, as indicated by empirical estimates, overlapped to the extent that they could limit or block fluid transport through the inter-lappet clefts. Our estimates indicate that boundary layer occlusion of fluid transport through the inter-lappet clefts occurred throughout the ephyral pulsation cycle-i.e., boundary layer thickness was always equal to or greater than gap distance (Fig. 5) - and our kinematic data led us to expect limited fluid flow through the clefts at any time during ephyral bell pulsation. This result is consistent with literature examining the "leakiness" of setal arrays that predict cylindrical setae with dimensions (i.e., gap to lappet diameter ratio $\leq 1$ ) and fluid regimes ( $\operatorname{Re} 0.5-10)$ similar to those of swimming ephyrae would have leakiness values of less than $20 \%$ (Hansen and Tiselius, 1992; Koehl, 1993, 2001).

These quantitative estimates were confirmed by flow visualizations of ephyral swimming. High-speed ( $250 \mathrm{fps}$ ) video recordings of fluorescein dye transport around a swimming ephyra demonstrated boundary layer occlusion of the interlappet clefts. The viscous boundary layer between the lappets was evident as a thin film of fluid that connected the lappet tips and appeared as "webbing" that persisted throughout the bell pulsation cycle (Fig. 6). The conformation of this webbing was dynamic and altered with direction and speed of lappet motion during bell pulsation. The boundary layer webbing folded outward, away from the oral surface as the lappets contracted, and inward, toward the oral surface, as the lappets relaxed to 

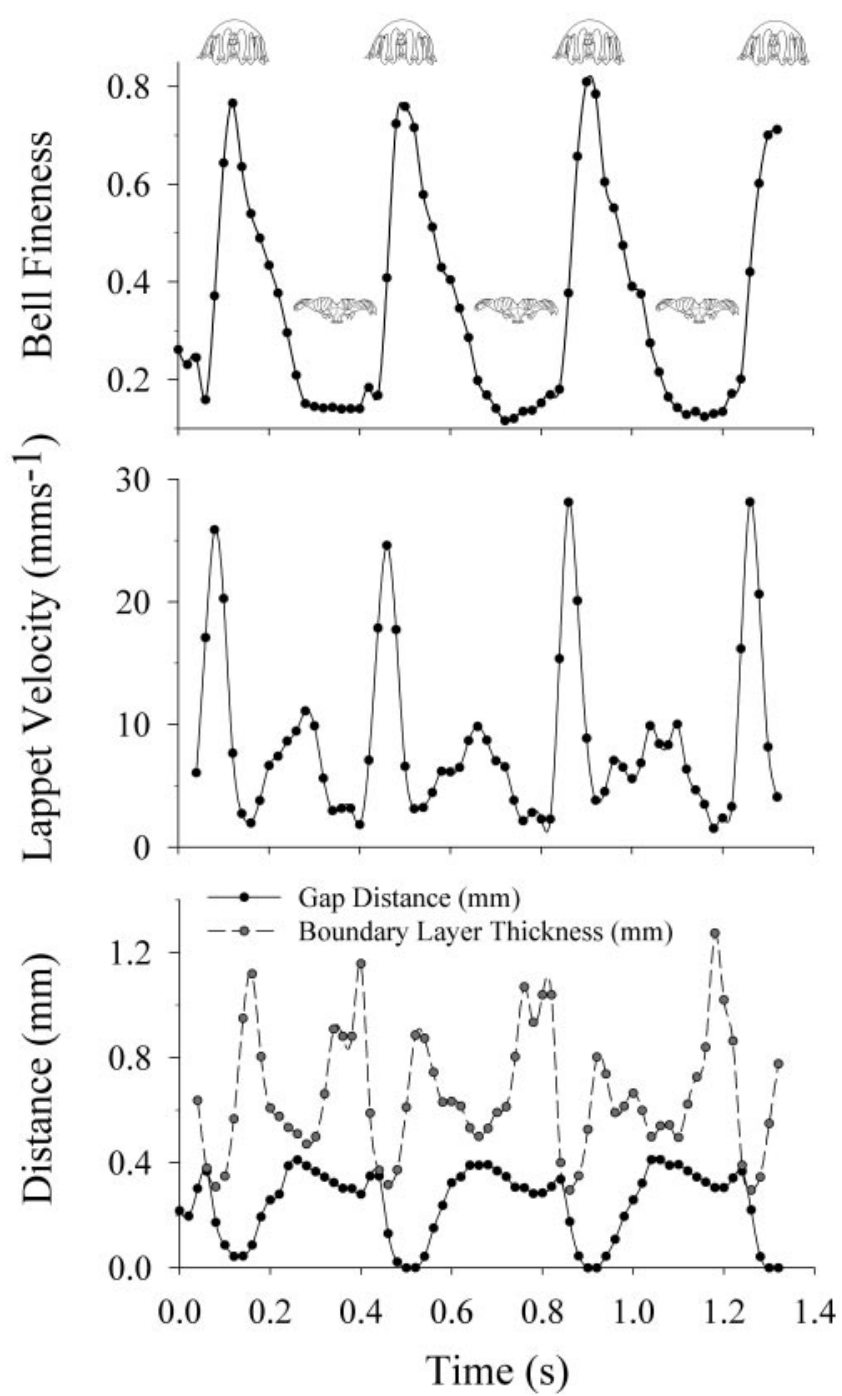

Figure 5. Kinematic profile of an ephyra $(0.32 \mathrm{~cm}$ diameter) illustrating bell fineness (top panel), lappet velocity (middle panel), inter-lappet gap distance and estimated boundary layer thickness (bottom panel) over three full bell pulsations. The boundary layer thicknesses of adjacent lappets were combined to calculate the overall boundary layer thickness. Note that the boundary later thickness remains higher than the inter-lappet gap distance during bell pulsation, indicating that boundary layers of adjacent lappets impede fluid flow between the lappets during swimming.

the starting position of bell pulsation (Fig. 7 and supplementary video 1, http://www.biolbull.org/supplemental/).

Although our focus was on the hydrodynamic functioning of the inter-lappet clefts, these traits arise from the general condition of boundary layer influences around the ephyra. These conditions were evident in dye visualization of ephyral wakes (supplementary video 1, http://www.biolbull. org/supplemental/). Boundary layers were thickest around the lappets themselves, and the highest lappet velocities during bell contraction were associated with shedding a portion of the dye-marked fluids surrounding the lappet. This corresponded to the period when estimated boundary layer thickness was at a minimum. As this fluid was shed, the ephyra moved forward, leaving behind it a series of dye-marked fluid "tracks" that resemble the outlines of the lappets (Fig. 7). These tracks possess little apparent circulation and did not form full vortices. The composite wake of an ephyrae visualized using dye was a series of these low-circulation tracks that were shed primarily during the contraction phase of bell pulsation (Fig. 7 and supplementary video 1, http://www.biolbull.org/supplemental/).

\section{Developmental alterations in bell morphology}

Increases in bell diameter that accompany growth influenced the fluid regimes surrounding swimming ephyrae (Fig. 4). High Re values diminish the dimensions of the boundary layers relative to the lappets they surround. Consequently, increased bell diameters influenced the boundary-layer-dependent webbing traversing the inter-lappet clefts (Fig. 7). Isometric growth by ephyrae would entail transitioning of the lappets from a functionally continuous surface to a sieve when overall bell diameter increased such that the larger inter-lappet gap distances exceed the relatively smaller boundary layer dimensions surrounding the

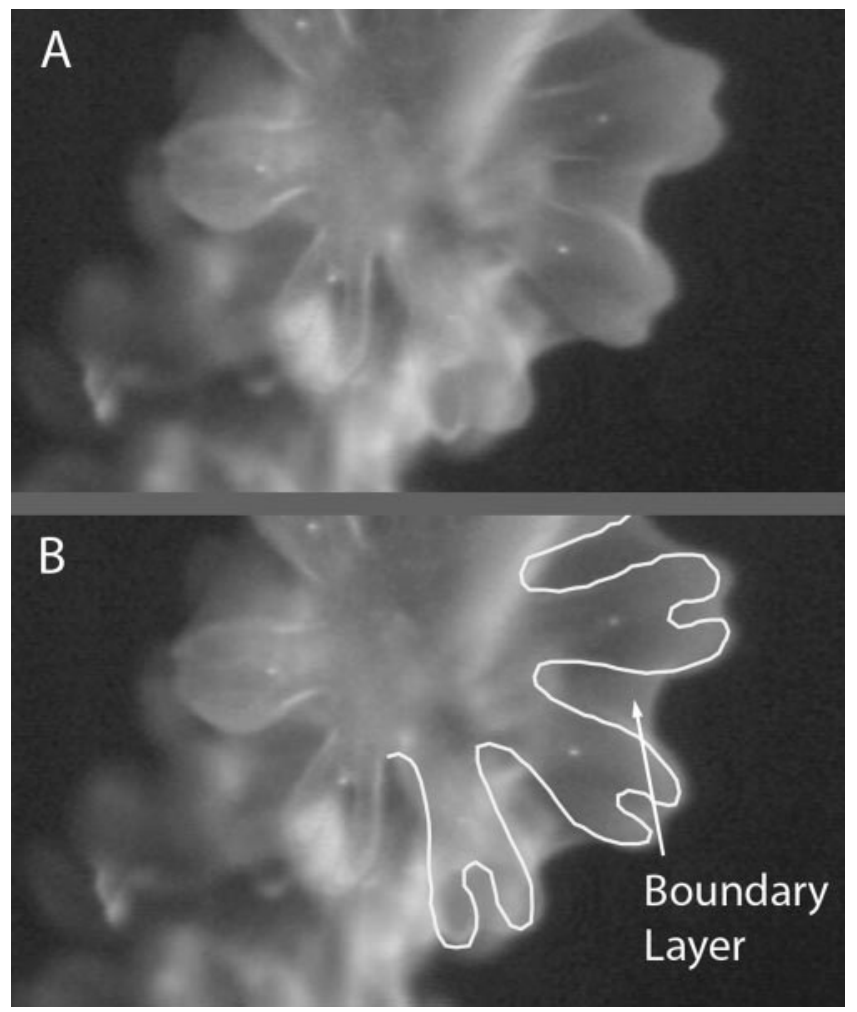

Figure 6. Dye visualization of boundary layer maintenance between lappets of a swimming ephyra when the bell is near full relaxation. The ephyra $(0.28 \mathrm{~cm}$ diameter) has passed through fluorescein dye. Dye remains along entire exumbrellar surface of ephyra (A), including both the lappets (outlined in panel B) and the inter-lappet spaces (see also supplementary video 1 , http://www.biolbull.org/supplemental/). 


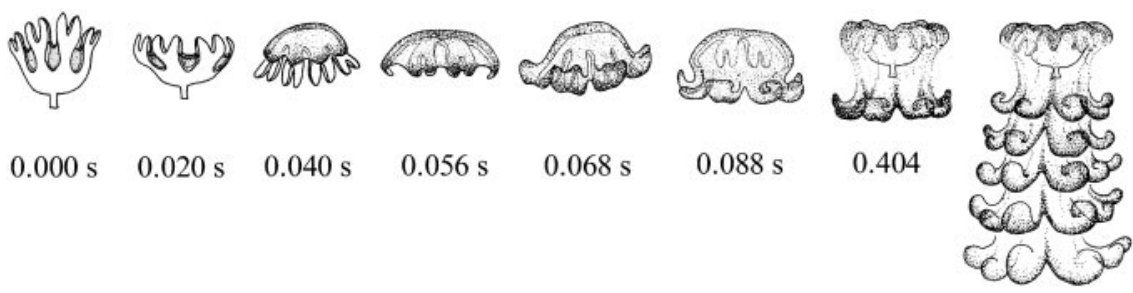

$2.180 \mathrm{~s}$

Figure 7. Dye visualization of flow around lappets during bell contraction of an ephyral Aurelia aurita $(0.32 \mathrm{~cm}$ diameter). Dye initially impinges on the aboral surface $(0.000 \mathrm{~s})$ and is then transported along the lappet surfaces during bell contraction $(0.02-0.056 \mathrm{~s})$. This process results in dye movement past the lappet tips and produces a characteristic series of impressions within the wake $(0.068-0.404 \mathrm{~s})$ that outline the positions of the lappet tips during previous contraction cycles. The far right image $(2.180 \mathrm{~s})$ results from deposition of these characteristic dye tracks during a series of bell pulsation cycles.

lappets. This expectation is hypothetical because A. aurita medusan development was typically allometric rather than isometric and the inter-lappet clefts are progressively filled in with tissue during the transition from ephyral to adult medusan morphologies (Figs. 1 and 8).

The developmental model indicates that allometric growth during ontogeny influences the hydrodynamic performance of scyphomedusan bells (Fig. 8). Decreases in the relative lappet boundary layer dimensions with increased bell diameter (and Re values) do not shift the functional role of the bell. Instead, the rate of tissue addition to the interlappet clefts during development maintained hydrodynamic continuity of the bell surface during swimming through the full range of transitional morphologies between ephyral and adult medusan life stages (Fig. 8).

\section{Discussion}

\section{Boundary layers and development}

Hydrodynamic interactions during morphological stages of development may help explain the persistence of ontogenetic patterns across scyphozoan taxa. The ephyral morphology, with its lappets and intervening clefts, is a conserved trait among scyphozoan medusae (e.g., Russell, 1970). One longstanding argument for conservation of larval morphologies within major animal taxa has been that deviation from ancestral developmental patterns may disrupt the orderly sequence of phylogenetically shared traits (Arthur, 1988). This perspective implies that later developmental stages can afford greater morphological flexibility because the traits common to the taxa, or phylotypic traits, are established during larval development. However, selection for larval morphological variations has been well documented, and it is clear that larvae are not exempt from morphological variation between even very closely related lineages such as echinoid echinoderms (e.g., sea urchins; Raff, 1996).

Conservation of a unique morphology such as the scyphozoan ephyral stage may involve selective advantages of that morphology. Boundary layer occlusion of flow through the inter-lappet clefts results in a functionally continuous bell disc for Aurelia aurita ephyrae, with minimal tissue allocation per unit bell diameter. The importance of the ephyral morphological design is related to an apparent developmental imperative for rapid bell expansion compared to overall biomass increase during ephyral growth (Bamstedt et al., 1999). Essentially, the ephyral morphology allows the developing medusae to maintain a continuous bell disc for swimming by utilizing hydrodynamic traits (boundary layer overlap) rather than requiring tissue allocation. Continued growth, accompanied by higher Re values and lower relative boundary layer thickness, requires progressively greater tissue allocation to the lappet cleft areas to maintain the hydrodynamic continuity of the bell through scyphomedusan development. Although boundary layer dynamics around arthropod setae have been well established for processes involving prey capture, olfaction, and propulsion (Koehl, 1993, 1995, 1998, 2001), ephyral bell development patterns demonstrate that boundary layer attributes may additionally enable organisms to conserve biomass while maintaining functionality (i.e., ability to swim).

\section{Size and propulsion}

The changes in Reynolds number that occur throughout the development of scyphomedusae have important implications for medusan propulsion. The rowing propulsion characteristic of adult $A$. aurita is dominated by unsteady forces acting on the bell as a consequence of bell motion in fluids dominated by inertial forces. The oscillatory contractions and relaxations of the bell of adult A. aurita create starting and stopping vortices, respectively, with opposite rotation that interact to transfer momentum to the surrounding fluid and thrust the medusae through the water with high propulsive efficiency (Dabiri et al., 2005). The shape and the kinematics of the bell determine interactions of starting and stopping vortices and, consequently, the amount of 

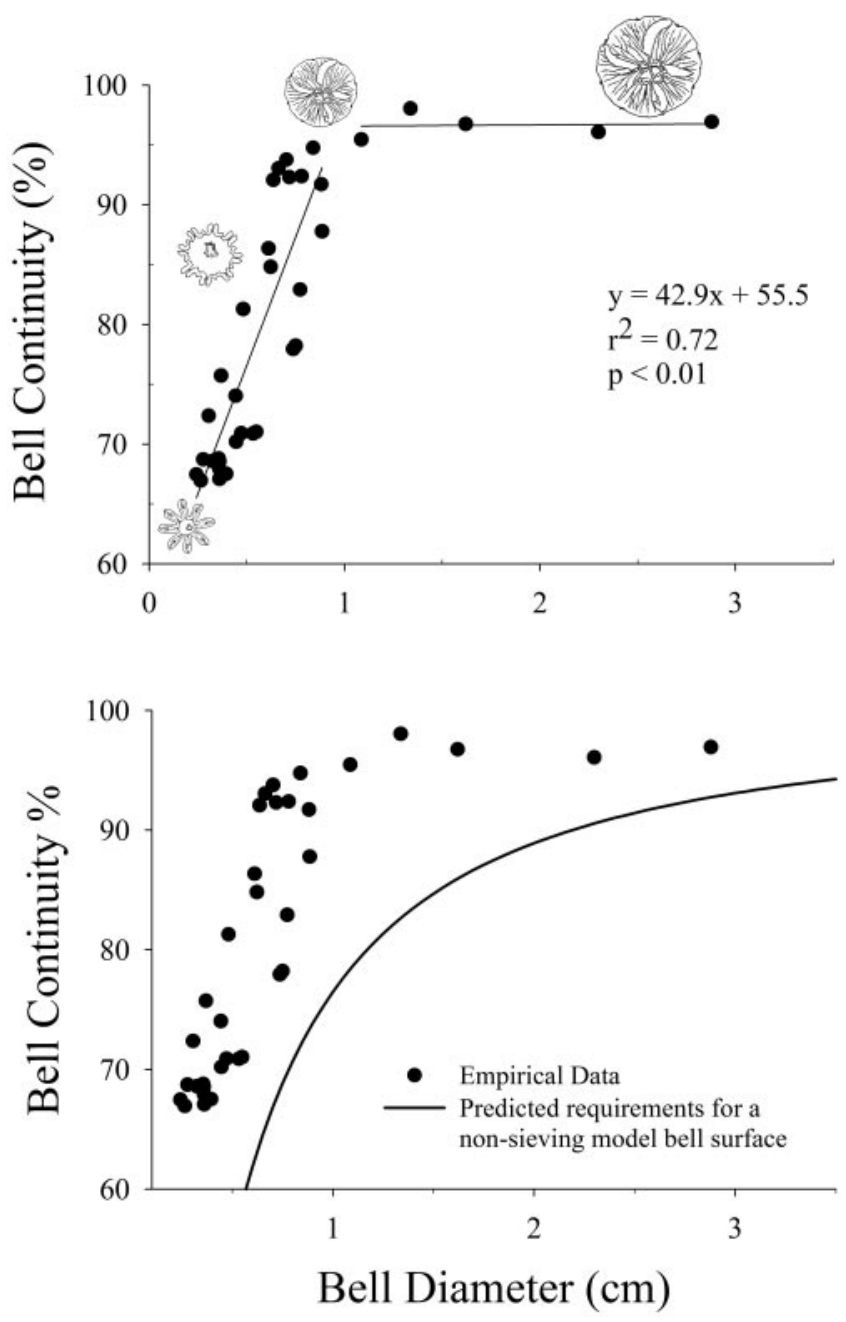

Figure 8. Relationship between bell continuity and development of Aurelia aurita. (Top) Alterations in swimming bell continuity during development of Aurelia aurita medusae $(n=35)$. Regression equation refers to the increase in bell continuity during early growth; at diameters greater than $1 \mathrm{~cm}$ there is no increase in bell continuity (represented by flat horizontal line). Probability value is the result of a one-way ANOVA of original and fitted bell continuity data. (Bottom) Comparison of empirical data (same data as top panel) with model predictions (solid line) for maintenance of a continuous boundary layer between adjoining lappets. The model assumes eight lappets, a swimming frequency of $3 \mathrm{~Hz}$, and a constant of proportionality (C) of 0.8 . The model curve describes the lowest theoretically permissible level of morphological bell continuity that will allow the bell to function as a hydrodynamically continuous surface via maintenance of overlapping boundary layers between lappets. Note that the required morphological bell continuity increases with bell diameter (and, therefore, Re) and that the distribution of empirically measured values resembles the general shape of the model curve. Empirical values exceed the model values, implying that lappet boundary layers overlap sufficiently for flow occlusion between the lappets throughout development from ephyral to adult swimming bell forms.

thrust produced during each pulse. However, at the Reynolds numbers of small ephyrae, viscous forces are highly influential and the pulsating bells of ephyrae do not create circulating vortices in their wake (Fig. 7 and supplementary video 1, http://www.biolbull.org/supplemental/). At these small Reynolds numbers, inertial forces acting on a body may be less important for propulsion than are viscous forces (Williams, 1994b). While an analysis of propulsion was not the focus of this study, our observations of the wake and bell kinematics of swimming ephyrae suggest that ephyral $A$. aurita swim using a different mode of propulsion than larger medusae. Instead of the inertially dominated rowing propulsion described for adults (Dabiri et al., 2005), ephyral swimming may be better characterized as drag-based paddling or viscous rowing. In the latter case, the magnitude of thrust created during the power stroke is largely (if not solely) determined by the amount of drag acting on the contracting lappets (Williams, 1994a). The long stroke length that results from the unique bell kinematics of ephyrae contributes to the amount of thrust produced during each power stroke.

Maintenance of paddle function through development has important consequences for medusan feeding. Because the bell represents a paddle surface, whether due to tissue or hydrodynamic continuity, fluid and entrained prey flow around the bell margin during swimming of all scyphomedusan stages (Higgins et al., 2008). Scyphomedusae of all life stages pulse and swim essentially continuously (Costello et al., 1998), and the resulting flows bring preyladen fluids into contact with nematocyst-bearing capture surfaces. The nature of flow around the bell margins has been described for adults of a variety of scyphomedusae (Costello and Colin, 1995; Costello et al., 2008), but rarely for ephyrae. However, visualizing these flow patterns may help resolve some enigmatic prey-capture patterns by ephyrae. For example, Higgins et al. (2008) quantitatively mapped capture locations of the largely passively transported prey Artemia sp. by the scyphozoan Cyanea capillata, and found that most prey were captured on the ephyral manubrium. The manubrium is relatively small during the ephyral stage (Fig. 1) and presents a restricted surface area in comparison to the lappets or subumbrellar surfaces. However, fluid transport passed directly along the manubrium during bell relaxation (supplementary video 2, http://www. biolbull.org/supplemental/), and entrained prey may be concentrated adjacent to the manubrium and contact the surfaces. This capture-location distribution is a direct consequence of fluid transport pathways around the hydrodynamically continuous bell margin. Increased bell diameter entails alterations in flow regime that include not only higher Re flows and proportionately thinner boundary layers, but also increased circulation and vortex production at the bell margins (Higgins et al., 2008). These changes in fluid flows of mature medusae therefore entail alterations in prey transport and capture-location distributions (Dabiri et al., 2005; Higgins et al., 2008).

The importance of animal-fluid interactions during scyphomedusan development is not surprising in light of the 
connection between propulsion (Dabiri et al., 2005; Ichikawa et al., 2006) and adult scyphomedusan feeding (Costello and Colin, 1994, 1995; Ford et al., 1997; D'Ambra et al., 2001). More generally, there is strong reason to believe that hydrodynamic factors have played an influential role in the evolution of medusan morphology (Dabiri et al., 2007). These interactions have been integrated over a range of organizational levels within the Medusozoa (Costello et al., 2008) and provide insight into a variety of biomechanical and ecological patterns within medusan biology.

\section{Acknowledgments}

The authors are grateful for financial support for this research from the National Science Foundation and the Office of Naval Research (OCE 9103309, OCE 0623508, N000140810654 to JHC; OCE-0351398 and OCE-0623534 to SPC; OCE-0623475 to JOD). We are grateful to E. Abbott for her assistance with artwork. We also thank S. Spina and the jellyfish crew at the New England Aquarium for their generous support in providing animals for study.

\section{Literature Cited}

Arthur, W. 1988. A Theory of the Evolution of Development. John Wiley, Chichester, England.

Bamstedt, U., J. Lane, and M. B. Martinussen. 1999. Bioenergetics of ephyra larvae of the scyphozoan jellyfish Aurelia aurita in relation to temperature and salinity. Mar. Biol. 135: 89-98.

Bartol, I. K., P. S. Krueger, J. T. Thompson, and W. J. Stewart. 2008. Swimming dynamics and propulsive efficiency of squids throughout ontogeny. Integr. Comp. Biol. 48: 720-733.

Behrends, G., and G. Schneider. 1995. Impact of Aurelia aurita medusae (Cnidaria, Scyphozoa) on the standing stock and community composition of mesozooplankton in the Kiel Bight (western Baltic Sea). Mar. Ecol. Prog. Ser. 127: 39-45.

Cheer, A. Y. L., and M. A. R. Koehl. 1987a. Paddles and rakes: fluid flow through bristled appendages of small organisms. J. Theor. Biol. 129: $17-39$.

Cheer, A. Y. L., and M. A. R. Koehl. 1987b. Fluid flow through filtering appendages of insects. I.M.A. J. Math. Appl. Med. Biol. 4: 185-199.

Colin, S. P., and J. H. Costello. 2002. Morphology, swimming performance and propulsive mode of six co-occurring hydromedusae. J. Exp. Biol. 205: 427-437.

Costello, J. H., and S. P. Colin. 1994. Morphology, fluid motion and predation by the scyphomedusa Aurelia aurita. Mar. Biol. 121: 327334.

Costello, J. H., and S. P. Colin. 1995. Flow and feeding by swimming scyphomedusae. Mar. Biol. 124: 399-406.

Costello, J. H., E. Klos, and M. D. Ford. 1998. In situ time budgets of the scyphomedusae Aurelia aurita, Cyanea sp., and Chrysaora quinquecirrha. J. Plankton Res. 20: 383-391.

Costello, J. H., S. P. Colin, and J. O. Dabiri. 2008. Medusan morphospace: phylogenetic constraints, biomechanical solutions, and ecological consequences. Invertebr. Biol. 127: 265-290.

Dabiri, J. O., S. P. Colin, J. H. Costello, and M. Gharib. 2005. Flow patterns generated by oblate medusan swimmers: in situ observation and analysis. J. Exp. Biol. 208: 1257-1265.

Dabiri, J. O., S. P. Colin, and J. H. Costello. 2007. Morphological diversity of medusan lineages constrained by animal-fluid interactions. J. Exp. Biol. 210: 1868-1873.

D'Ambra, I., J. H. Costello, and F. Bentivegna. 2001. Flow and prey capture by the scyphomedusa Phyllorhiza punctata von Lendenfeld 1884. Hydrobiologia 451: 223-227.

Daniel, T. L. 1983. Mechanics and energetics of medusan jet propulsion. Can. J. Zool. 61: 1406-1420.

Ellington, C. P. 1975. Non-steady-state aerodynamics of the flight of Encorsia formosa. Pp. 783-786 in Swimming and Flying in Nature, Vol. 2 T. Y.-T. Wu, C. J. Brokaw, and L. Brennan, eds. Plenum Press, New York.

Fernier, M. C., and B. Gaylord. 2008. Flexibility foils filter function: structural limitations on suspension feeding. J. Exp. Biol. 211: 3563-3572.

Ford, M. D., J. H. Costello, K. B. Heidelberg, and J. E. Purcell. 1997. Swimming and feeding by the Scyphomedusa Chrysaora quinquecirrha. Mar. Biol. 129: 355-362.

Hansen B., and P. Tiselius. 1992. Flow through the feeding structures of suspension feeding zooplankton: a physical model approach. J. Plankton Res. 14: 821- 834.

Higgins, J. E., III, M. D. Ford, and J. H. Costello. 2008. Transitions in morphology, nematocyst distribution, fluid motions, and prey capture during development of the scyphomedusa Cyanea capillata. Biol. Bull. 214: 29-41.

Ichikawa, S., Y. Yazaki, and O. Mochizuki. 2006. Flow induced by jellyfish. Phys. Fluids 18: 091104-1.

Kawahara, M., S. Uye, K. Ohtsu, and H. Iizumi. 2006. Unusual population explosion of the giant jellyfish Nemopilema nomurai (Scyphozoa: Rhizostomeae) in East Asian waters. Mar. Ecol. Prog. Ser. 307: $161-173$.

Koehl, M. A. R. 1993. Hairy little legs: feeding, smelling, and swimming at low Reynolds number. Contemp. Math. 141: 33-64.

Koehl, M. A. R. 1995. Fluid flow through hair-bearing appendages: feeding, smelling, and swimming at low and intermediate Reynolds number. In Biological Fluid Dynamics, Soc. Exp. Biol. Symp. 49: 157-182, C.P. Ellington and T. J. Pedley, eds. Company of Biologists, Cambridge.

Koehl, M. A. R. 1998. Small scale hydrodynamics of feeding appendages of marine animals. Oceanography 11: 10-12.

Koehl, M. A. R. 2001. Transitions in function at low Reynolds number: hair bearing animal appendages. Math. Methods Appl. Sci. 24: 1523-1532.

Koehl, M. A. R. 2006. The fluid mechanics of arthropod sniffing in turbulent odor plumes. Chem. Senses 31: 93-105.

Kramp, P. L. 1961. Synopsis of the medusae of the world. J. Mar. Biol. Assoc. UK 40: 1-469.

Loudon, C., B. A. Best, and M. A. R. Koehl. 1994. When does motion relative to neighboring surfaces alter the flow through an array of hairs? J. Exp. Biol. 193: 233-254

Raff, R. A. 1996. The Shape of Life: Genes, Development and the Evolution of Animal Form. University of Chicago Press, Chicago.

Russell, F. S. 1970. The Medusae of the British Isles. Cambridge University Press, Cambridge.

Sullivan, B. K., C. L. Suchman, and J. H. Costello. 1997. Mechanics of prey selection by ephyrae of the scyphomedusa Aurelia aurita. Mar Biol. 130: 213-222.

Vogel, S. 1994. Life in Moving Fluids. Princeton University Press, Princeton, NJ.

White, F. M. 1991. Viscous Fluid Flow. McGraw-Hill, New York.

Williams, T. A. 1994a. Locomotion in developing Artemia larvae: mechanical analysis of antennal propulsors based on large-scale physical models. Biol. Bull. 187: 156-163.

Williams, T. A. 1994b. A model of rowing propulsion and the ontogeny of locomotion in Artemia larvae. Biol. Bull. 187: 164-173.

Yen, J., M. J. Weissburg, and M. H. Doall. 1998. The fluid physics of signal perception by mate-tracking copepods. Philos. Trans. R. Soc. Lond. 353: 787-804. 